\title{
Differences in Nutritional Status Between Very Mild Alzheimer's Disease Patients and Healthy Controls
}

\author{
Marcel G.M. Olde Rikkert ${ }^{\mathrm{a}, 1, *}$, Frans R. Verhey ${ }^{\mathrm{b}}$, John W.C. Sijben ${ }^{\mathrm{c}}$, Femke H. Bouwman ${ }^{\mathrm{d}, 1}$, \\ Paul L.J. Dautzenberg ${ }^{\mathrm{e}}$, Mirian Lansink ${ }^{\mathrm{c}}$, Walther M.W. Sipers ${ }^{\mathrm{f}}$, Dieneke Z.B. van Asselt ${ }^{\mathrm{g}}$, \\ Anneke M.J. van Hees ${ }^{c}$, Martijn Stevens ${ }^{\mathrm{h}}$, Bruno Vellas ${ }^{\mathrm{i}}$ and Philip Scheltens ${ }^{\mathrm{j}}$ \\ ${ }^{a}$ Radboud Alzheimer Center, Department of Geriatric Medicine, Radboud University Hospital, Nijmegen, \\ The Netherlands \\ ${ }^{\mathrm{b}}$ Alzheimer Center Limburg, Maastricht University Medical Center, Maastricht, The Netherlands \\ ${ }^{\mathrm{c}}$ Nutricia Research, Utrecht, The Netherlands \\ ${ }^{\mathrm{d}}$ Neurology Department, Catharina Ziekenhuis, Eindhoven, The Netherlands \\ e Geriatrics Department, Jeroen Bosch Ziekenhuis, 's-Hertogenbosch, The Netherlands \\ ${ }^{\mathrm{f}}$ Department of Geriatric Medicine, Orbis Medisch Centrum, Sittard, The Netherlands \\ ${ }^{\mathrm{g}}$ Department of Geriatric Medicine, Medical Center Leeuwarden, Leeuwarden, The Netherlands \\ ${ }^{\mathrm{h}}$ Neurology Department, Tergooiziekenhuizen Blaricum, Blaricum, The Netherlands \\ ${ }^{\mathrm{i}}$ Gerontopole, INSERM U 1027, Toulouse, France \\ ${ }^{\mathrm{j}}$ Alzheimer Center, VU University Medical Center, Amsterdam, The Netherlands
}

Handling Associate Editor: Deborah Gustafson

Accepted 21 January 2014

\begin{abstract}
.
Background: Studies on the systemic availability of nutrients and nutritional status in Alzheimer's disease (AD) are widely available, but the majority included patients in a moderate stage of AD.

Objective: This study compares the nutritional status between mild AD outpatients and healthy controls.

Methods: A subgroup of Dutch drug-naïve patients with mild AD (Mini-Mental State Examination (MMSE) $\geq 20$ ) from the Souvenir II randomized controlled study (NTR1975) and a group of Dutch healthy controls were included. Nutritional status was assessed by measuring levels of several nutrients, conducting the Mini Nutritional Assessment (MNA ${ }^{\circledR}$ ) questionnaire and through anthropometric measures.

Results: In total, data of 93 healthy cognitively intact controls (MMSE 29.0 [23.0-30.0]) and 79 very mild AD patients $(\mathrm{MMSE}=25.0[20.0-30.0])$ were included. Plasma selenium $(p<0.001)$ and uridine $(p=0.046)$ levels were significantly lower in $\mathrm{AD}$ patients, with a similar trend for plasma vitamin $\mathrm{D}(p=0.094)$ levels. In addition, the fatty acid profile in erythrocyte membranes was different between groups for several fatty acids. Mean MNA screening score was significantly lower in AD patients $(p=0.008)$, but not indicative of malnutrition risk. No significant differences were observed for other micronutrient or anthropometric parameters.

Conclusion: In non-malnourished patients with very mild AD, lower levels of some micronutrients, a different fatty acid profile in erythrocyte membranes and a slightly but significantly lower MNA screening score were observed. This suggests that subtle differences in nutrient status are present already in a very early stage of $\mathrm{AD}$ and in the absence of protein/energy malnutrition.
\end{abstract}

Keywords: Alzheimer's disease, fatty acids, healthy volunteers, micronutrients, nutritional status, protein-energy malnutrition

\footnotetext{
${ }^{1}$ Present address: Alzheimer Center, VU University Medical Center, Amsterdam, The Netherlands.

${ }^{*}$ Correspondence to: Marcel Olde Rikkert, MD, PhD, Radboud Alzheimer Center, Department of Geriatric Medicine,
}

Radboud University Hospital, P.O. Box 9101, 6500 HB Nijmegen, The Netherlands. Tel.: +31 2436167 72; Fax: +31 2436174 08; E-mail: M.Olde-Rikkert@ger.umcn.nl. 


\section{INTRODUCTION}

Alzheimer's disease (AD) is a progressive, neurodegenerative disorder with unknown etiology. There are multiple risk factors for $\mathrm{AD}$ including age, certain genetic alleles (e.g., apolipoprotein E4), and specific nutritional characteristics [1-3]. Epidemiological studies suggest that a low intake of $n-3$ fatty acids, B-vitamins, and antioxidants increases the risk of $\mathrm{AD}[4,5]$. Several nutrients are hypothesized to play a role in the pathological processes of AD. For instance, the n-3 long-chain polyunsaturated fatty acid (n-3 LC-PUFA) docosahexaenoic acid (DHA) reduces abnormal amyloid- $\beta(\mathrm{A} \beta)$ and tau processing [6]. In addition, antioxidants like vitamin $\mathrm{E}$ have been shown to protect against $A \beta$-induced oxidative stress and to stabilize neuronal membranes [7]. These observations suggest that systemic availability of several nutrients is of importance in AD.

$\mathrm{AD}$ patients are frequently reported to have lower plasma levels of certain nutrients compared with cognitively intact controls. These lower plasma nutrient levels may be due to reduced daily consumption, increased nutrient use and/or a different metabolism in $\mathrm{AD}$ [8]. Recently, a systematic review and metaanalysis compared plasma levels of vitamins, minerals, trace elements, and fatty acids in AD patients with those in cognitive intact controls [9]. Significantly lower plasma levels of vitamin A, C, E, folate, and vitamin $\mathrm{B} 12$ were found in $\mathrm{AD}$ patients, while there was a trend for lower levels of vitamin D and zinc [9]. About half of the studies included in this review mentioned the stage of the disease of the included AD patients [9], reporting average Mini-Mental State Examination (MMSE) scores ranging from 8 to 21.5. This suggests that limited data are available on nutrient levels in very mild AD patients. Besides lower micronutrient levels, (risk on) protein/energy malnutrition frequently occurs in cognitively impaired elderly subjects [10], and data suggest a positive association between the presence of (risk of) protein/energy malnutrition and the stage of AD [11-14]. Protein/energy malnutrition can potentially be associated with differential blood nutrient levels [15]. Furthermore, (risk of) protein/energy malnutrition as assessed by the Mini Nutritional Assessment $\left(\mathrm{MNA}^{\circledR}\right)$ questionnaire has been shown to be associated with disease progression in very mild $\mathrm{AD}$ patients [16], indicating the importance of studying nutritional status in the early stage of $\mathrm{AD}$.

The aim of the current study was to compare the nutritional status between mild AD patients and healthy controls. We assessed nutritional status by measuring levels of several micronutrients and fatty acids. We used the MNA questionnaire and anthropometric measures to determine (risk of) protein/energy malnutrition. The current study is a substudy of the 24-week, double-blind, randomized, controlled, multicenter Souvenir II study in which the effect of a medical food on memory performance of mild $\mathrm{AD}$ patients was investigated [17].

\section{MATERIALS AND METHODS}

\section{Study population}

The study population of this exploratory Souvenir II substudy consisted of a subgroup of patients with mild $\mathrm{AD}$ from the double-blind, randomized, controlled, multi-center, multi-country Souvenir II study and a group of healthy controls, all recruited in the Netherlands. The Dutch Trial Registration Number for the Souvenir II study is NTR1975.

\section{Patients}

A total of $84 \mathrm{AD}$ patients across nine study centers agreed to participate. The methodology of the Souvenir II study has been described in detail previously [17]. Briefly, major eligibility criteria included 1) diagnosis of probable AD according to the National Institute of Neurological and Communicative Disorders and Stroke and the Alzheimer's Disease and Related Disorders Association criteria [18], 2) mild AD as defined by a MMSE score $\geq 20,3$ ) age $\geq 50$ years, 4 ) being drugnaive for $\mathrm{AD}$ medication (cholinesterase inhibitor or $N$-methyl-D-aspartate receptor antagonist, 5) the presence of a responsible caregiver, and 6) the provision of written informed consent from both the patient and caregiver.

\section{Healthy controls}

A total of 98 healthy controls were included across seven (out of nine) Dutch study centers. Healthy controls could be either caregivers, other contacts of the patients or other volunteers and met the following eligibility criteria: 1 ) age $\geq 50$ years, 2) no current diagnosis of $\mathrm{AD}, 3$ ) no other condition that might interfere with the definition 'healthy person' according to the investigator's judgment, 4) no participation in another interventional clinical study, and 5) the provision of written informed consent. 


\section{Nutritional supplement use}

In addition to the eligibility criteria described above, the following exclusion criteria regarding the use of nutritional supplements or dietary habits were applied to both the inclusion of AD patients and healthy controls: 1) use within two months prior to study participation of a) n-3 fatty acid containing supplements or b) oily fish (when consumed more than twice a week) and 2) use within one month prior to study participation of a) vitamins B, C and/or E $>200 \%$ of recommended daily intake or $b$ ) high energy and/or high protein nutritional supplements and/or medical foods.

\section{Study procedures}

For the current analysis, the authors used data on nutritional status collected at the baseline visit of the Souvenir II study for the AD patients and data collected at a single time-point for the healthy controls. In addition, information on demographic data and the use of nutritional supplements was collected from all subjects. At all centers, trained research nurses performed all assessments.

\section{Outcome measures}

Plasma micronutrients and fatty acids in plasma phospholipids and erythrocyte membrane: Non-fasting blood samples were taken to determine plasma folate, vitamins B6 and B12, choline, homocysteine (Hcy), uridine, vitamins $\mathrm{A}, \mathrm{D}$, and $\mathrm{E}$, selenium, albumin, and plasma phospholipid fatty acids levels. In addition, erythrocytes were collected from the same blood sample to determine fatty acid levels in the erythrocyte membrane.

Anthropometry: Measures of anthropometry included calf circumference and body weight and height to calculate body mass index (BMI) (=body weight $[\mathrm{kg}] /$ body height $[\mathrm{m}]^{2}$ ). Calf circumference was assessed to the nearest $0.1 \mathrm{~cm}$ of the largest part of the left lower leg using calibrated equipment, with the subject in a sitting position, knee and ankle at a $90^{\circ}$ angle and with the muscles relaxed. Body height was measured, without shoes, to the nearest $\mathrm{cm}$. Body weight was measured, without shoes and heavy clothing, to the nearest $0.1 \mathrm{~kg}$.

Mini Nutritional Assessment: The MNA ${ }^{\circledR}$ questionnaire was used as a measure of nutritional status [19-21]. The questionnaire contains a 6-item screening part and a 12-item assessment part. All subjects completed the MNA screening part. When subjects scored $\leq 11$ out of 14 points on the screening part (indicative of increased risk for protein/energy malnutrition), the 12-item assessment part was completed as well and a total score was calculated (MNA total $=$ sum of scores on screening part and assessment part; maximum score $=30$, a score between 17 and 23.5 is indicative of risk for protein/energy malnutrition, a score lower than 17 is indicative for malnutrition). BMI and calf circumference are part of the MNA screening and total score, respectively.

\section{Subject characteristics and nutritional supplement use}

Subject characteristics that were collected for the study included age, gender, education (years of formal education after finishing primary school), and the MMSE score (a short cognitive test with a score ranging from 0 [severe cognitive deficit] to 30 [no cognitive deficit]). Furthermore, the health status of the healthy controls was assessed using the Cumulative Illness Rating Scale for Geriatrics (CIRS-G), which measures chronic medical conditions while considering the severity of chronic diseases in elderly [22]. Diseases are scored by organ systems and grouped into 14 categories. Each category is scored on severity, ranging from 0 (no problem) to 4 (extremely severe). For this study, the CIRS-G total score was calculated (i.e., the sum of scores on the 14 categories, maximum score $=56$ ). If applicable, information was collected on the use of nutritional supplements.

\section{Ethics}

Written informed consent was obtained from patients and their caregivers and the healthy controls prior to study participation. The Ethics Committee of each participating study center reviewed and approved the protocol. The study was conducted in accordance with the Declaration of Helsinki, the International Conference on Harmonization Guidelines for Good Clinical Practice as appropriate for nutritional products and the local laws and regulations of the Netherlands.

\section{Biochemical analyses}

Blood was collected in tubes containing ethylenediaminetetraacetic acid. All samples were centrifuged $\left(1300 \mathrm{~g}, 15 \mathrm{~min}, 4^{\circ} \mathrm{C}\right)$, and plasma and erythrocyte aliquots were stored at $-80^{\circ} \mathrm{C}$ until analysis at a central laboratory. Plasma folate and vitamin B12 levels were determined using a competitive protein binding ligand assay, plasma B6 levels were measured by high-performance liquid chromatography 
(HPLC). HPLC-electrochemical detection of plasmafree choline was performed according to a method adapted from Fossati et al. [23] as described previously [24]. Plasma albumin was determined using a colorimetric kit, and plasma selenium levels were measured using graphite furnace atomic absorption spectrometry. A chemiluminescent microparticle immuno assay (ARCHITECT assay) was used to determine plasma vitamin D (total 25-hydroxyvitamin D) levels. Plasma vitamin A (retinol) and vitamin E ( $\alpha$-tocopherol) levels were determined simultaneously by HPLC, using ultraviolet-absorbance for detection of retinol and fluorometric properties for detection of $\alpha$-tocopherol, by comparing with standard solutions [25]. For the determination of plasma Hcy levels, thiol amino acids (free and proteinbound) were reduced with tri-n-butylphosphine. After precipitation with trichloroacetic acid, thiol groups were derivatized with ammonium 7-fluorobenzo-2oxa-1,3-diazole-4-sulfonate, followed by separation using HPLC with a fluorescence detector [26, 27]. In order to determine plasma uridine levels, perchloric acid was added to the sample. Uridine was extracted by vortexing the solution, followed by separation from other nucleotides/nucleosides using reversed-phase HPLC [28]. Uridine was quantified by measuring its absorbance compared with a standard. Fatty acid compositions of the erythrocyte lipid fraction and the plasma phospholipid fraction were analyzed qualitatively on a gas chromatograph after extraction of the lipids from the erythrocytes/plasma (plasma phospholipids were separated from the other lipid classes in plasma by solid phase extraction) and a methylation step [29-32].

The analysis of plasma Hcy levels was repeated due to relatively high interassay variations in the analyses. Results from the second analysis were used for statistical comparisons due to lower interassay variations in the second compared with the first analysis. Also, the analysis of plasma uridine levels was performed twice, because the assay is sensitive to variation. Pooled data from these analyses were used for statistical comparisons as there were no clear indications to use either one of the analyses.

\section{Statistical analyses}

Statistical analyses were performed using SAS $^{\circledR}$ software (SAS Enterprise Guide 4.3 for Windows, SAS Institute Inc., Cary, NC, USA). Data are presented as means \pm standard deviation (SD) unless stated otherwise. Statistical significance was set at $p<0.05$.
Given the exploratory nature of the study, no sample size calculations were performed. Despite the attempt to select a group of healthy controls with a mean age comparable to the AD patients, there was an age difference at baseline between the healthy controls $(n=98)$ and AD patients $(n=84)$ (respectively $70.4 \pm 10.1$ versus $74.2 \pm 7.6$ years, $p=0.005$ ). To overcome this imbalance at baseline, it was decided to exclude the five oldest $\mathrm{AD}$ patients and the five youngest healthy controls from the dataset prior to the main statistical analyses. Indeed, this resulted in a better balance between groups with respect to age (Table 1), while other subject characteristics at baseline did not change. Therefore, data from 93 healthy controls and 79 AD patients were used for the analyses presented here.

Differences between AD patients and healthy controls were primarily analyzed using an independent samples $t$-test. The non-parametric Mann-Whitney test was used for parameters with a non-normal distribution. As a sensitivity analysis, additional between-group analyses were performed using analysis of covariance (ANCOVA) to correct for the potential confounders 'age' (continuous; years), 'nutritional supplement use' (dummy variable; yes/no), 'use of lipid-modifying agents' (dummy variable; yes/no), and 'years of education' (continuous; years). As some subjects used nutritional supplements, a specific dummy variable for nutritional supplement use was defined for each outcome parameter. Results of the ANCOVA analyses were compared with those of the $t$-test. No correction for multiple testing was performed, and, in line with the exploratory character of the study, differences in levels between groups were tested for each parameter separately using an alpha level of 0.05 .

Two AD patients and one healthy control were excluded from the analysis of vitamin B6, vitamin B12, folate, choline, and Hcy because of the recent use of vitamin B12 injections, which might interfere with plasma levels of these parameters.

\section{RESULTS}

Subject characteristics of both the AD patients and the healthy controls are shown in Table 1. There were no significant differences between groups for age ( $t$-test, $p=0.125$ ) and gender (Fisher's Exact test, $p=0.760)$. Years of education was significantly higher in healthy controls compared with AD patients (median [range], 5.0 [0.0-25.0] versus 4.0 [0.0-16.0], MannWhitney test, $p=0.005$ ). The total MMSE score was significantly higher in healthy controls compared with 
Table 1

Subject characteristics

\begin{tabular}{|c|c|c|c|}
\hline & Healthy controls $(n=93)$ & Mild AD $(n=79)$ & $p$-value \\
\hline Age, years [range] & $71.5(9.3)[5390]$ & $73.4(7.2)[54-84]$ & $0.125^{*}$ \\
\hline Male, $n(\%)$ & $43(46.2 \%)$ & $39(49.4 \%)$ & $0.760^{\dagger}$ \\
\hline Years of education beyond primary school & $5.0[0.0-25.0]$ & $4.0[0.0-16.0]$ & $0.005^{\ddagger}$ \\
\hline MMSE, total score & $29.0[23.0-30.0]$ & $25.0[20.0-30.0]$ & $<0.001^{\ddagger}$ \\
\hline CIRS-G, total score & 3.76 & - & $\mathrm{n} / \mathrm{a}$ \\
\hline Nutritional supplement use, $n(\%)$ & $13(14.0 \%)$ & $12(15.2 \%)$ & $0.832^{\dagger}$ \\
\hline Multivitamins & $4(4.3 \%)$ & $1(1.3 \%)$ & $0.376^{\dagger}$ \\
\hline Vitamin E & 0 & $1(1.3 \%)$ & $0.459^{\dagger}$ \\
\hline Vitamin D and analogues & $4(4.3 \%)$ & $2(2.5 \%)$ & $0.688^{\dagger}$ \\
\hline Vitamin B complex, plain & 0 & $1(1.3 \%)$ & $0.459^{\dagger}$ \\
\hline Hydroxocobalamin & $1(1.1 \%)$ & $2(2.5 \%)$ & $0.594^{\dagger}$ \\
\hline Folic acid & 0 & $1(1.3 \%)$ & $0.459^{\dagger}$ \\
\hline Calcium & $4(4.3 \%)$ & $5(6.3 \%)$ & $0.734^{\dagger}$ \\
\hline Other & $4(4.3 \%)$ & 0 & $0.126^{\dagger}$ \\
\hline Lipid-modifying agents use, $n(\%)$ & $20(21.5 \%)$ & $31(39.2 \%)$ & $0.013^{\dagger}$ \\
\hline
\end{tabular}

AD, Alzheimer's disease; CIRS-G, Cumulative Illness Rating Scale for Geriatrics; MMSE, Mini-Mental State Examination; -, not measured, n/a, not applicable. Data are mean (standard deviation) or median [range]. ${ }^{*} T$-test; ${ }^{\dagger}$ Fisher’s exact test; ${ }^{\ddagger}$ Mann-Whitney test.

AD patients (median [range], 29.0 [23.0-30.0] versus 25.0 [20.0-30.0], Mann-Whitney test, $p<0.001$ ), suggestive of a cognitively intact, healthy control group versus a very early AD patient group. Moreover, the CIRS-G score in the healthy controls (3.76) was indicative of low co-morbidity. The number of subjects using one or more nutritional supplements was comparable between healthy controls and AD patients $(13(14.0 \%)$ versus $12(15.2 \%)$, Fisher's Exact test, $p=0.832)$, while the number of subjects using one or more lipidmodifying agents was higher in the group of $\mathrm{AD}$ patients compared with healthy controls (31 (39.2\%) versus $20(21.5 \%)$, Fisher's Exact test, $p=0.013)$.

\section{Plasma micronutrients}

Results for the comparison of plasma micronutrient levels between the AD patients and the healthy controls are shown in Table 2. Plasma selenium and uridine levels were significantly lower in AD patients compared with healthy controls ( $t$-test, respectively $p<0.001$ and $p=0.046$ ). There was a trend for lower plasma vitamin D levels in AD patients compared with healthy controls $(t$-test, $p=0.084)$. No significant differences were observed between the healthy controls and $\mathrm{AD}$ patients for plasma levels of folate, choline, vitamin B6, vitamin B12, Hcy, vitamin A, vitamin E, and albumin.

Correction for the potential confounders did not affect any of the observed differences, except for the difference in plasma vitamin D levels, which was not significant after correction for the confounders (ANCOVA, $\mathrm{F}(1,166)=2.34, p=0.128)$.
Table 2

Descriptive statistics for plasma micronutrients, anthropometrics, and malnutrition scoring for mild stage AD patients and healthy controls

\begin{tabular}{lccr}
\hline & $\begin{array}{c}\text { Healthy controls } \\
(n=93)\end{array}$ & $\begin{array}{c}\text { Mild AD } \\
(n=79)\end{array}$ & $p$-value* \\
\hline Plasma micronutrients & $13.59(5.27)$ & $13.84(5.65)$ & 0.771 \\
Homocysteine $(\mu \mathrm{M})$ & $17.53(8.59)$ & $16.07(10.12)$ & 0.309 \\
Folate $(\mathrm{nM})$ & $8.45(2.31)$ & $8.79(2.19)$ & 0.345 \\
Choline $(\mu \mathrm{M})$ & $314.5(98.4)$ & $348.4(188.8)$ & 0.158 \\
Vitamin B12 $(\mathrm{pM})$ & $61.28(44.73)$ & $57.85(47.27)$ & 0.631 \\
Vitamin B6 $(\mathrm{nM})$ & $3.38(1.29)$ & $3.03(0.95)$ & 0.046 \\
Uridine $(\mu \mathrm{M})$ & $1.18(0.26)$ & $1.04(0.24)$ & $<0.001$ \\
Selenium $(\mu \mathrm{M})$ & $3.30(0.69)$ & $3.46(0.73)$ & 0.151 \\
Vitamin A $(\mu \mathrm{M})$ & $52.92(22.23)$ & $47.30(19.69)$ & 0.084 \\
Vitamin D $(\mathrm{nM})$ & $32.89(7.23)$ & $31.89(9.07)$ & 0.432 \\
Vitamin E $(\mu \mathrm{M})$ & & & \\
Anthropometrics & & & \\
Body weight $(\mathrm{kg})$ & $73.79(11.96)$ & $74.89(12.79)$ & 0.560 \\
Body height $(\mathrm{m})$ & $1.70(0.08)$ & $1.69(0.08)$ & 0.361 \\
BMI $\left(\mathrm{kg} / \mathrm{m}^{2}\right)$ & $25.4(3.6)$ & $26.2(4.1)$ & 0.212 \\
Calf circumference $(\mathrm{cm})$ & $35.5(3.1)$ & $35.9(3.2)$ & 0.390 \\
& & & \\
Malnutrition scoring & & & \\
MNA screening score & $13.2(1.2)$ & $12.6(1.5)$ & 0.008 \\
MNA total score & $24.8(1.6)$ & $23.4(2.7)$ & 0.171 \\
Albumin $(\mathrm{g} / \mathrm{L})$ & $40.51(2.83)$ & $41.14(2.76)$ & 0.141 \\
\hline AD, Alzheimer's & & &
\end{tabular}

AD, Alzheimer's disease; BMI, body mass index; MNA, Mini Nutritional Assessment. Data are mean (standard deviation). *Independent samples $t$-test, except for MNA total score (see $\dagger$ ) 'MNA total score: Healthy controls $(n=10)$, AD $(n=10)$. Fisher's Exact test. Fatty acids in erythrocyte membrane and plasma
phospholipids

Table 3 shows the results of the between-group comparisons of the erythrocyte and plasma fatty acid 
Table 3

Descriptive statistics for fatty acids in erythrocyte membranes and plasma phospholipids

\begin{tabular}{|c|c|c|c|c|c|c|}
\hline & \multicolumn{3}{|c|}{ Erythrocyte fatty acids } & \multicolumn{3}{|c|}{ Plasma phospholipid fatty acids } \\
\hline & $\begin{array}{l}\text { Healthy controls } \\
\quad(n=93)\end{array}$ & $\begin{array}{l}\text { Mild AD } \\
(n=79)\end{array}$ & $p$-value* & $\begin{array}{l}\text { Healthy controls } \\
\quad(n=93)\end{array}$ & $\begin{array}{l}\text { Mild AD } \\
(n=79)\end{array}$ & $p$-value* \\
\hline $\mathrm{EPA}(\%)$ & $0.98(0.40)$ & $0.97(0.44)$ & 0.849 & $1.21(0.62)$ & $1.15(0.72)$ & 0.523 \\
\hline DHA $(\%)$ & $3.44(0.99)$ & $2.99(1.14)$ & 0.006 & $3.63(0.93)$ & $3.55(0.96)$ & 0.572 \\
\hline DPA $(\%)$ & $1.78(0.36)$ & $1.64(0.54)$ & 0.046 & $0.94(0.17)$ & $0.96(0.17)$ & 0.509 \\
\hline $\mathrm{DHA}+\mathrm{EPA}(\%)$ & $4.42(1.30)$ & $3.95(1.48)$ & 0.028 & $4.84(1.38)$ & $4.69(1.54)$ & 0.511 \\
\hline n-3 LC-PUFA (\%) & $6.20(1.54)$ & $5.59(1.92)$ & 0.024 & $5.78(1.44)$ & $5.65(1.60)$ & 0.577 \\
\hline Palmitic acid (\%) & $24.82(1.40)$ & $26.64(2.76)$ & $<0.001$ & $27.90(1.49)$ & $28.52(1.28)$ & 0.005 \\
\hline Stearic acid $(\%)$ & $9.00(0.72)$ & $9.12(0.84)$ & 0.309 & $13.19(1.24)$ & $12.87(1.09)$ & 0.077 \\
\hline Elaidic acid (\%) & $0.18(0.11)$ & $0.23(0.11)$ & 0.006 & $0.13(0.05)$ & $0.12(0.06)$ & 0.119 \\
\hline Oleic acid $(\%)$ & $15.80(1.72)$ & $15.59(1.54)$ & 0.387 & $9.12(1.20)$ & $9.18(1.47)$ & 0.788 \\
\hline Cis-vaccenic acid (\%) & $1.14(0.16)$ & $1.14(0.17)$ & 0.981 & $1.34(0.20)$ & $1.36(0.22)$ & 0.515 \\
\hline Linoleic acid $(\%)$ & $15.01(2.53)$ & $13.06(2.41)$ & $<0.001$ & $21.10(2.86)$ & $20.61(2.71)$ & 0.255 \\
\hline Gamma linolenic acid (\%) & $0.15(0.10)$ & $0.09(0.09)$ & $<0.001$ & $0.12(0.06)$ & $0.13(0.07)$ & 0.227 \\
\hline Alpha linolenic acid (\%) & $0.28(0.10)$ & $0.16(0.09)$ & $<0.001$ & $0.22(0.09)$ & $0.18(0.06)$ & $<0.001$ \\
\hline Stearidonic acid $(\%)$ & $0.09(0.04)$ & $0.11(0.13)$ & 0.231 & $0.05(0.01)$ & $0.05(0.01)$ & 0.632 \\
\hline Dihomo gamma linolenic acid (\%) & $1.49(0.30)$ & $1.30(0.33)$ & $<0.001$ & $2.97(0.77)$ & $2.91(0.68)$ & 0.586 \\
\hline Arachidonic acid $(\%)$ & $10.94(1.43)$ & $9.76(2.69)$ & $<0.001$ & $9.47(1.84)$ & $9.91(2.38)$ & 0.194 \\
\hline Cis docosapentaenoic acid (\%) & $0.63(0.14)$ & $0.70(0.25)$ & 0.026 & $0.21(0.06)$ & $0.21(0.08)$ & 0.790 \\
\hline
\end{tabular}

AD, Alzheimer's disease; DHA, docosahexaenoic acid; DPA, docosapentaenoic acid; EPA, eicosapentaenoic acid; n-3 LC-PUFA, n-3 long-chain polyunsaturated fatty acids. Data are mean (standard deviation). ${ }^{*}$ Independent samples $t$-test.

profiles. The percentage of DHA, docosapentaenoic (DPA), DHA + eicosapentaenoic acid (EPA), linoleic acid, alpha, gamma and dihomo gamma linolenic acid, arachidonic acid, and n-3 LC-PUFA of total fatty acids in the erythrocyte membrane was significantly lower in the $\mathrm{AD}$ patients versus healthy controls, whereas the percentage of palmitic acid, elaidic acid, and cisdocosapentaenoic acid was higher in AD patients. The proportion of the other analyzed fatty acids in the erythrocyte membrane, including EPA, was not significantly different between groups. In plasma phospholipids, the percentage of alpha linolenic acid of total fatty acids was significantly lower and the percentage of palmitic acid significantly higher in AD patients versus healthy controls. The other fatty acids in plasma phospholipids were not significantly different between groups.

Correction for the potential confounders did not affect the results of the fatty acid analyses, except for the percentage of elaidic acid in plasma phospholipids, which was significantly lower in AD patients versus healthy controls after correction for the confounders (ANCOVA, $\mathrm{F}(1,159)=3.96, p=0.048)$.

\section{Anthropometry}

Calf circumference, body weight, height, and BMI were not significantly different between AD patients and healthy controls (Table 2). Also after correction for potential confounders, no differences between groups were observed.

\section{Mini nutritional assessment}

Results from the MNA questionnaire are shown in Table 2. The MNA screening score was significantly lower in the AD patients compared with the healthy controls $(12.6 \pm 1.5$ versus $13.2 \pm 1.2, t$-test, $p=0.008$ ). The MNA total score (applied to the subset of subjects with an initial low MNA screening score of $\leq 11, n=10$ in each group) was not significantly different between groups ( $t$-test, $p=0.171$ ). The mean MNA total score, however, was below the cut-off point for normal nutritional status (i.e., <24.0) in the AD patients $(23.4 \pm 2.7 / n=5$ scored $<24.0)$, but not in the healthy controls $(24.8 \pm 1.6 / n=1$ scored $<24.0)$, suggesting increased risk for protein/energy malnutrition in only a small subgroup of AD patients.

Correction for potential confounders did not affect any of the observed differences.

\section{DISCUSSION}

We found that plasma levels of selenium and uridine were lower and plasma levels of vitamin D tended to be lower in very mild $\mathrm{AD}$ patients $(\mathrm{MMSE}=25.3)$ compared with healthy controls. The fatty acid profile in erythrocyte membranes also showed differences between groups, including a lower proportion of docosahexaenoic and linoleic acid and total n-3 LCPUFA and a higher proportion of palmitic and elaidic acid in AD patients. The studied AD population was not at nutritional risk: their MNA screening score was 
$\geq 12$ ( $<12$ indicates risk on protein/energy malnutrition) [10], their BMI was $>23 \mathrm{~kg} / \mathrm{m}^{2}$ [33], their calf circumference $>31 \mathrm{~cm} \mathrm{[10],} \mathrm{and} \mathrm{their} \mathrm{albumin}>35 \mathrm{~g} / \mathrm{L}$. Therefore, the observed differences in nutrient levels seem unlikely to have originated from protein/energy malnutrition. However, based on this study we cannot exclude that the nutritional differences measured are caused by differences in intake secondary to the cognitive decline. Other studies have proven compensatory neuronal activity in $\mathrm{AD}$, which make an intrinsic shortage of certain micronutrients linked to increased needs more likely [34]. Moreover, specific nutrient intake deficiencies and weight loss may occur in AD despite adequate or even increased caloric intake, possibly due to defects in systemic nutrient homeostasis such as malabsorption and decreased interest in specific nutritional components [35]. Although unintended weight loss frequently occurs in AD (approximately $40 \%$ of patients) and has been reported during all stages of the disease $[36,37]$, the mild AD patients in this study did not suffer from energy malnutrition and had a relatively high mean BMI. This suggests that caloric intake was adequate in the currently studied mild AD population, but this was not specifically measured. It has recently been shown that BMI might even increase in prevalent $\mathrm{AD}$ and that changes in BMI during disease may depend on the patient's initial BMI [38]. Our results from the MNA questionnaire are in agreement with a recent study of the MNA in Dutch AD patients that showed that outpatients of a memory clinic showed no protein-energy malnutrition, while a subgroup (14\%) showed higher risk on such malnutrition [39]. In addition, the findings on nourishment status in the currently studied AD patients are in line with literature data, which suggest a positive association between prevalence of (risk of) protein/energy malnutrition and stage of $\mathrm{AD}[11-14,39]$.

Many studies have compared levels of nutrients between $\mathrm{AD}$ patients and controls. In a recent metaanalysis of such trials, a similar trend as in this study was found for lower vitamin D levels in AD patients [9]. Furthermore, lower levels of vitamin A, B12, E, and folate in $\mathrm{AD}$ patients compared with cognitive intact elderly controls were observed. In the present study, no differences between groups in the levels of these vitamins were observed, which may be explained by several factors. Firstly, in the current study very mild AD patients were included, whereas studies in the meta-analysis included patients with a more advanced stage of the disease: differences in certain nutrients might only become apparent in more advanced stages of the disease. Secondly, differences in dietary intake or habits between studies performed in different countries may contribute to these findings and the current study was performed in one country only. Finally, the sample size may have been too small to detect differences between groups in certain nutrients.

Lower selenium levels as currently found are also described in other [40, 41], but not in all studies [42, 43]. Selenium is a micronutrient which is involved in several molecular pathways that are thought to be important in the progression of $\mathrm{AD}$ [44]. It is, for instance, part of the antioxidant enzyme glutathionperoxidase which helps to protect lipid precursors and the resulting membrane components from lipid peroxidation. Lower plasma selenium levels in AD patients compared with healthy controls may have an association with the process of oxidative stress known to be present in $\mathrm{AD}$. To compensate for a possible increased use of selenium in $\mathrm{AD}$, a higher intake might be necessary.

Several differences in fatty acid levels in erythrocyte membranes were observed between groups in the present study, including lower proportions of n6 and n-3 polyunsaturated fatty acids in mild AD patients. These differences are in line with reported lower dietary intake of linoleic and alpha linolenic acid and DHA in early AD compared with age-matched controls [45]. The observed lower circulating levels of n- 6 fatty acids are generally believed not to be of concern due to their high availability in foods through plant oils and subsequent high and probably abundant tissue levels [46]. In addition, we found higher levels of the trans fatty acid elaidic acid in erythrocyte membranes of the AD patients. Trans fatty acids have been suggested to enhance amyloidogenic processing of the amyloid precursor protein and increase the production and aggregation of $A \beta$ in vitro [47]. However, the suggested link between trans fatty acid intake and AD risk or cognitive decline is not consistently supported by cohort studies showing either a positive association [48] or no association $[49,50]$.

In the current study, no significant differences in plasma DHA, EPA, and n-3 LC-PUFA levels were found between groups. Levels of n-3 LC-PUFA in plasma, however, are a poorer marker of long term dietary intake than levels in erythrocyte membranes [51]. The observed lower erythrocyte DHA and total n3 LC-PUFA in the mild AD patients are consistent with previous observations [52]. Recently, reduced activity of the last step enzyme in DHA synthesis pathway, peroxisomal D-bifunctional protein was found in the liver of $\mathrm{AD}$ patients and this coincided with lower DHA levels in the brain and liver tissue [53]. This metabolic 
change may contribute to the lower DHA and not EPA erythrocyte membrane levels as currently found and is consistent with a recent meta-analytic review reporting lower plasma levels of DHA and total n-3 LC-PUFA in dementia patients [54].

The plasma levels of uridine were lower in $\mathrm{AD}$ patients in the present study. This finding confirms the results of a very recent study reporting lower plasma uridine levels in $\mathrm{AD}$ patients versus healthy controls [55]. Although the cause of these lower levels of uridine is unclear, it has been speculated that de novo synthesis of uridine in the liver may be reduced in $\mathrm{AD}$ [8]. The lower uridine observed in the plasma of $A D$ patients is likely to result in less transport of uridine into the brain as uridine readily enters the brain via the blood-brain barrier high affinity transporter of nucleosides CNT2 [56]. Uridine is, via the Kennedy pathway, a precursor in the synthesis of phospholipids in neuronal membranes, which are depleted in $\mathrm{AD}[57,58]$. Combined dietary enrichment of uridine and DHA has been reported to promote the synthesis of brain phospholipids, hippocampal dendritic spines, and synaptic proteins, all prerequisites for synaptogenesis [59]. In $\mathrm{AD}$, cerebrospinal fluid uridine levels [60] and hippocampal levels of DHA [61, 62] were found to be lower than in controls, which together may reflect a reduced capacity for neuronal membrane synthesis and may result in inability to compensate for the synaptic loss associated with $\mathrm{AD}$ and be associated with lower levels in the circulation. Although tissue target levels of uridine and DHA are not well defined for the general population, they should probably be higher for people with $\mathrm{AD}$ provided their role in compensational neuronal membrane synthesis. Further research is needed to elucidate the cause and possible clinical implications of lower circulating uridine and DHA levels in AD.

Decreased levels of certain nutrients as observed in $\mathrm{AD}$ patients suggest a potential role for the supplementation of specific nutrients in the management of AD. Until now, several intervention studies investigated the effects of supplementation with single nutrients, for instance vitamin B12, vitamin E, or n-3 LC-PUFA in dementia patients, showing no or little improvements of cognitive function and other outcomes [63-65]. The outcomes of single nutrient studies may be explained by the fact that nutrients most likely act in a synergistic way [66]. The findings of the current study are in line with this, since several nutrients, rather than a single nutrient, were observed to be present in lower levels. An intervention with a specific combination of nutrients in the form of a medical food has been shown to improve memory performance of drug-naive patients with mild $\mathrm{AD}$ and has been suggested to preserve functional connectivity in $\mathrm{AD}[17,67]$. Together, these data may suggest that combinations of nutrients can be more powerful than single nutrients, as there may be a positive interaction between them. A similar synergistic effect of a complex combination of nutrients has recently been described for the Mediterranean diet enriched with walnut oil for cardiovascular endpoints [68].

The present study has some limitations: 1) Control subjects are not precisely matched for age and gender. The average age of $\mathrm{AD}$ patients is almost 2 years higher and there are slightly more men in the AD group (49.4\% versus $46.2 \%)$. These differences may have influenced the results. However, analyses on data of 66 pairs of age- and gender-matched subjects and excluding subjects using nutritional supplements yielded similar results (data not shown). 2) No data were collected on dietary intake of the study subjects, so the possible contribution of (differences in) dietary intake (specific (micro)nutrients and/or caloric intake) on the results cannot be determined. 3) Due to the exploratory character of the study, no correction for multiple testing was performed. To confirm current study findings, further research is warranted. 4) To avoid the influence of regional differences in nutrient levels via for instance different dietary habits or food fortification, this substudy was performed in one small country with relatively homogenous food habits, the Netherlands. This may, however, limit its representation for other regions.

In conclusion, the study results showed lower levels of some micronutrients, a different fatty acid profile in erythrocyte membranes, and a slightly, but significantly lower MNA screening score in very mild AD patients compared with healthy controls, whereas the $\mathrm{AD}$ patients were neither malnourished nor at risk of malnutrition. These data suggest that in a very early stage of $\mathrm{AD}$ and in the absence of protein/energy malnutrition, subtle differences in nutrient status are present as compared to healthy controls. Given the proposed role of nutrients and nourishment status in $\mathrm{AD}$ pathology and progress, these data need to be corroborated in an independent sample, possibly also including preclinical and prodromal stages of AD to study when these changes occur in the disease progress.

\section{ACKNOWLEDGMENTS}

We sincerely thank the patients, their caregivers, and the healthy control persons for their participation in the study. 
Study design and planning, data analysis and interpretation were carried out in conjunction with the sponsor, Nutricia Research, on behalf of Nutricia Advanced Medical Nutrition. The sponsor also provided funding for the research and data collection. The Souvenir II study was further supported by the NL Food \& Nutrition Delta project, FND N 10003.

Authors' disclosures available online (http://www.jalz.com/disclosures/view.php?id=2118).

\section{REFERENCES}

[1] Citron M (2002) Alzheimer's disease: Treatments in discovery and development. Nat Neurosci 5 Suppl, 10551057.

[2] Gillette Guyonnet S, Abellan Van Kan G, Andrieu S, Barberger Gateau P, Berr C, Bonnefoy M, Dartigues JF, de Groot L, Ferry M, Galan P, Hercberg S, Jeandel C, Morris MC, Nourhashemi F, Payette H, Poulain JP, Portet F, Roussel AM, Ritz P, Rolland Y, Vellas B (2007) IANA task force on nutrition and cognitive decline with aging. $J$ Nutr Health Aging 11, 132-152.

[3] Seshadri S, Drachman DA, Lippa CF (1995) Apolipoprotein E epsilon 4 allele and the lifetime risk of Alzheimer's disease. What physicians know, and what they should know. Arch Neurol 52, 1074-1079.

[4] Barberger-Gateau P, Raffaitin C, Letenneur L, Berr C, Tzourio C, Dartigues JF, Alperovitch A (2007) Dietary patterns and risk of dementia: The Three-City cohort study. Neurology 69 , 1921-1930.

[5] Luchsinger JA, Tang MX, Miller J, Green R, Mayeux R (2007) Relation of higher folate intake to lower risk of Alzheimer disease in the elderly. Arch Neurol 64, 86-92.

[6] Kamphuis PJ, Scheltens P (2010) Can nutrients prevent or delay onset of Alzheimer's disease? J Alzheimers Dis 20, 765775.

[7] Pocernich CB, Lange ML, Sultana R, Butterfield DA (2011) Nutritional approaches to modulate oxidative stress in Alzheimer's disease. Curr Alzheimer Res 8, 452-469.

[8] Mi W, van Wijk N, Cansev M, Sijben JW, Kamphuis PJ (2013) Nutritional approaches in the risk reduction and management of Alzheimer's disease. Nutrition 29, 1080-1089.

[9] Lopes da Silva S, Vellas B, Elemans S, Luchsinger J, Kamphuis P, Yaffe K, Sijben J, Groenendijk M, Stijnen $\mathrm{T}$ (2013) Plasma nutrient status of Alzheimer's disease patients compared to cognitive intact elderly controls: A systematic review and meta-analysis. Alzheimers Dement, doi: 10.1016/j.jalz.2013.1005.1771

[10] Guigoz Y (2006) The Mini Nutritional Assessment (MNA) review of the literature-What does it tell us? J Nutr Health Aging 10, 466-485; discussion 485-467.

[11] Buffa R, Mereu RM, Putzu PF, Floris G, Marini E (2010) Bioelectrical impedance vector analysis detects low body cell mass and dehydration in patients with Alzheimer's disease. J Nutr Health Aging 14, 823-827.

[12] Gillioz AS, Villars H, Voisin T, Cortes F, Gillette-Guyonnet S, Andrieu S, Gardette V, Nourhashemi F, Ousset PJ, Jouanny P, Vellas B (2009) Spared and impaired abilities in communitydwelling patients entering the severe stage of Alzheimer's disease. Dement Geriatr Cogn Disord 28, 427-432.

[13] Guerin O, Soto ME, Brocker P, Robert PH, Benoit M, Vellas B (2005) Nutritional status assessment during Alzheimer's disease: Results after one year (the REAL French Study Group). J Nutr Health Aging 9, 81-84.

[14] Sandman PO, Adolfsson R, Nygren C, Hallmans G, Winblad B (1987) Nutritional status and dietary intake in institutionalized patients with Alzheimer's disease and multiinfarct dementia. J Am Geriatr Soc 35, 31-38.

[15] Calvo I, Olivar J, Martinez E, Rico A, Diaz J, Gimena M (2012) MNA(R) Mini Nutritional Assessment as a nutritional screening tool for hospitalized older adults; rationales and feasibility. Nutr Hosp 27, 1619-1625.

[16] Ousset PJ, Nourhashemi F, Reynish E, Vellas B (2008) Nutritional status is associated with disease progression in very mild Alzheimer disease. Alzheimer Dis Assoc Disord 22, 6671.

[17] Scheltens P, Twisk JW, Blesa R, Scarpini E, von Arnim CA, Bongers A, Harrison J, Swinkels SH, Stam CJ, de Waal H, Wurtman RJ, Wieggers RL, Vellas B, Kamphuis PJ (2012) Efficacy of Souvenaid in mild Alzheimer's disease: Results from a randomized, controlled trial. J Alzheimers Dis 31, 225236.

[18] McKhann G, Drachman D, Folstein M, Katzman R, Price D, Stadlan EM (1984) Clinical diagnosis of Alzheimer's disease: Report of the NINCDS-ADRDA Work Group under the auspices of Department of Health and Human Services Task Force on Alzheimer's Disease. Neurology 34, 939-944.

[19] Vellas B, Villars H, Abellan G, Soto ME, Rolland Y, Guigoz Y, Morley JE, Chumlea W, Salva A, Rubenstein LZ, Garry P (2006) Overview of the MNA-Its history and challenges. $J$ Nutr Health Aging 10, 456-463; discussion 463-455.

[20] Rubenstein LZ, Harker JO, Salva A, Guigoz Y, Vellas B (2001) Screening for undernutrition in geriatric practice: Developing the short-form mini-nutritional assessment (MNA-SF). J Gerontol A Biol Sci Med Sci 56, M366-M372.

[21] Guigoz Y (2006) The Mini Nutritional Assessment (MNA) review of the literature-What does it tell us? J Nutr Health Aging 10, 466-485; discussion 485-487.

[22] Miller MD, Paradis CF, Houck PR, Mazumdar S, Stack JA, Rifai AH, Mulsant B, Reynolds CF, 3rd (1992) Rating chronic medical illness burden in geropsychiatric practice and research: Application of the Cumulative Illness Rating Scale. Psychiatry Res 41, 237-248.

[23] Fossati T, Colombo M, Castiglioni C, Abbiati G (1994) Determination of plasma choline by high-performance liquid chromatography with a postcolumn enzyme reactor and electrochemical detection. J Chromatogr B Biomed Appl 656, 59-64.

[24] van Wijk N, Watkins CJ, Bohlke M, Maher TJ, Hageman RJ, Kamphuis PJ, Broersen LM, Wurtman RJ (2012) Plasma choline concentration varies with different dietary levels of vitamins B6, B12 and folic acid in rats maintained on cholineadequate diets. Br J Nutr 107, 1408-1412.

[25] Catignani GL (1986) An HPLC method for the simultaneous determination of retinol and alpha-tocopherol in plasma or serum. Methods Enzymol 123, 215-219.

[26] Kuo K, Still R, Cale S, McDowell I (1997) Standardization (external and internal) of HPLC assay for plasma homocysteine. Clin Chem 43, 1653-1655.

[27] Krijt J, Vackova M, Kozich V (2001) Measurement of homocysteine and other aminothiols in plasma: Advantages of using tris(2-carboxyethyl)phosphine as reductant compared with tri-n-butylphosphine. Clin Chem 47, 1821-1828.

[28] Wynants J, Van Belle H (1985) Single-run high-performance liquid chromatography of nucleotides, nucleosides, and major purine bases and its application to different tissue extracts. Anal Biochem 144, 258-266. 
[29] Folch J, Lees M, Sloane Stanley GH (1957) A simple method for the isolation and purification of total lipides from animal tissues. J Biol Chem 226, 497-509.

[30] Kolarovic L, Fournier NC (1986) A comparison of extraction methods for the isolation of phospholipids from biological sources. Anal Biochem 156, 244-250.

[31] Bligh EG, Dyer WJ (1959) A rapid method of total lipid extraction and purification. Can J Biochem Physiol 37, 911917.

[32] Morrison WR, Smith LM (1964) Preparation of fatty acid methyl esters and dimethylacetals from lipids with boron fluoride-methanol. J Lipid Res 5, 600-608.

[33] Faxen-Irving G, Basun H, Cederholm T (2005) Nutritional and cognitive relationships and long-term mortality in patients with various dementia disorders. Age Ageing 34, 136-141.

[34] Meulenbroek O, Rijpkema M, Kessels RP, Rikkert MG, Fernandez G (2010) Autobiographical memory retrieval in patients with Alzheimer's disease. Neuroimage 53, 331-340.

[35] Aziz NA, van der Marck MA, Pijl H, Olde Rikkert MG, Bloem BR, Roos RA (2008) Weight loss in neurodegenerative disorders. J Neurol 255, 1872-1880.

[36] Gillette-Guyonnet S, Nourhashemi F, Andrieu S, de Glisezinski I, Ousset PJ, Riviere D, Albarede JL, Vellas B (2000) Weight loss in Alzheimer disease. Am J Clin Nutr 71, 637S642S.

[37] Buchman AS, Wilson RS, Bienias JL, Shah RC, Evans DA, Bennett DA (2005) Change in body mass index and risk of incident Alzheimer disease. Neurology 65, 892-897.

[38] Gu Y, Scarmeas N, Cosentino S, Brandt J, Albert M, Blacker D, Dubois B, Stern Y (2013) Change in body mass index before and after Alzheimer's disease onset. Curr Alzheimer Res, doi: CAR-EPUB-57541 [pii].

[39] Droogsma E, van Asselt DZ, van Steijn JH, Schuur T, Huinink EJ (2013) Effect of long-term treatment with galantamine on weight of patients with Alzheimer's dementia. J Nutr Health Aging 17, 461-465.

[40] Vural H, Demirin H, Kara Y, Eren I, Delibas N (2010) Alterations of plasma magnesium, copper, zinc, iron and selenium concentrations and some related erythrocyte antioxidant enzyme activities in patients with Alzheimer's disease. J Trace Elem Med Biol 24, 169-173.

[41] Cardoso BR, Ong TP, Jacob-Filho W, Jaluul O, Freitas MID, Cozzolino SMF (2010) Nutritional status of selenium in Alzheimer's disease patients. Br J Nutr 103, 803-806.

[42] Basun H, Forssell LG, Wetterberg L, Winblad B (1991) Metals and trace elements in plasma and cerebrospinal fluid in normal aging and Alzheimer's disease. J Neural Transm Park Dis Dement Sect 3, 231-258.

[43] Meseguer I, Molina JA, Jimenez-Jimenez FJ, Aguilar MV, Mateos-Vega CJ, Gonzalez-Munoz MJ, de Bustos F, OrtiPareja M, Zurdo M, Berbel A, Barrios E, Martinez-Para MC (1999) Cerebrospinal fluid levels of selenium in patients with Alzheimer's disease. J Neural Transm 106, 309-315.

[44] Loef M, Schrauzer GN, Walach H (2011) Selenium and Alzheimer's disease: A systematic review. J Alzheimers Dis 26, 81-104.

[45] Shatenstein B, Kergoat MJ, Reid I (2007) Poor nutrient intakes during 1-year follow-up with community-dwelling older adults with early-stage Alzheimer dementia compared to cognitively intact matched controls. J Am Diet Assoc 107, 2091-2099.

[46] Hibbeln JR, Nieminen LR, Blasbalg TL, Riggs JA, Lands WE (2006) Healthy intakes of n-3 and n-6 fatty acids: Estimations considering worldwide diversity. Am J Clin Nutr 83, 1483S1493S.
[47] Grimm MO, Rothhaar TL, Grosgen S, Burg VK, Hundsdorfer B, Haupenthal VJ, Friess P, Kins S, Grimm HS, Hartmann T (2012) Trans fatty acids enhance amyloidogenic processing of the Alzheimer amyloid precursor protein (APP). J Nutr Biochem 23, 1214-1223.

[48] Morris MC, Evans DA, Bienias JL, Tangney CC, Bennett DA, Aggarwal N, Schneider J, Wilson RS (2003) Dietary fats and the risk of incident Alzheimer disease. Arch Neurol 60, 194-200.

[49] Engelhart MJ, Geerlings MI, Ruitenberg A, Van Swieten JC, Hofman A, Witteman JC, Breteler MM (2002) Diet and risk of dementia: Does fat matter? The Rotterdam Study. Neurology 59, 1915-1921.

[50] Naqvi AZ, Harty B, Mukamal KJ, Stoddard AM, Vitolins M, Dunn JE (2011) Monounsaturated, trans, and saturated Fatty acids and cognitive decline in women. J Am Geriatr Soc 59 837-843.

[51] Katan MB, Deslypere JP, van Birgelen AP, Penders M, Zegwaard M (1997) Kinetics of the incorporation of dietary fatty acids into serum cholesteryl esters, erythrocyte membranes, and adipose tissue: An 18-month controlled study. J Lipid Res 38, 2012-2022.

[52] Selley ML (2007) A metabolic link between Sadenosylhomocysteine and polyunsaturated fatty acid metabolism in Alzheimer's disease. Neurobiol Aging 28, 1834-1839.

[53] Astarita G, Jung KM, Berchtold NC, Nguyen VQ, Gillen DL, Head E, Cotman CW, Piomelli D (2010) Deficient liver biosynthesis of docosahexaenoic acid correlates with cognitive impairment in Alzheimer's disease. PLoS One 5 e12538.

[54] Lin PY, Chiu CC, Huang SY, Su KP (2012) A meta-analytic review of polyunsaturated fatty acid compositions in dementia. J Clin Psychiatry 73, 1245-1254.

[55] Trushina E, Dutta T, Persson XM, Mielke MM, Petersen RC (2013) Identification of altered metabolic pathways in plasma and CSF in mild cognitive impairment and Alzheimer's disease using metabolomics. PLoS One 8, e63644.

[56] Cansev M (2006) Uridine and cytidine in the brain: Their transport and utilization. Brain Res Rev 52, 389-397.

[57] Nitsch RM, Blusztajn JK, Pittas AG, Slack BE, Growdon JH, Wurtman RJ (1992) Evidence for a membrane defect in Alzheimer disease brain. Proc Natl Acad Sci U S A 89, 1671-1675.

[58] Pettegrew JW, Panchalingam K, Hamilton RL, McClure RJ (2001) Brain membrane phospholipid alterations in Alzheimer's disease. Neurochem Res 26, 771-782.

[59] Sakamoto T, Cansev M, Wurtman RJ (2007) Oral supplementation with docosahexaenoic acid and uridine- $5^{\prime}$ monophosphate increases dendritic spine density in adult gerbil hippocampus. Brain Res 1182, 50-59.

[60] Czech C, Berndt P, Busch K, Schmitz O, Wiemer J, Most V, Hampel H, Kastler J, Senn H (2012) Metabolite profiling of Alzheimer's disease cerebrospinal fluid. PLoS One 7, e31501.

[61] Soderberg M, Edlund C, Kristensson K, Dallner G (1991) Fatty acid composition of brain phospholipids in aging and in Alzheimer's disease. Lipids 26, 421-425.

[62] Prasad MR, Lovell MA, Yatin M, Dhillon H, Markesbery WR (1998) Regional membrane phospholipid alterations in Alzheimer's disease. Neurochem Res 23, 81-88.

[63] Eastley R, Wilcock GK, Bucks RS (2000) Vitamin B12 deficiency in dementia and cognitive impairment: The effects of treatment on neuropsychological function. Int $J$ Geriatr Psychiatry 15, 226-233. 
[64] Farina N, Isaac MG, Clark AR, Rusted J, Tabet N (2012) Vitamin E for Alzheimer's dementia and mild cognitive impairment. Cochrane Database Syst Rev 11, CD002854.

[65] Quinn JF, Raman R, Thomas RG, Yurko-Mauro K, Nelson EB, Van Dyck C, Galvin JE, Emond J, Jack CR Jr, Weiner M, Shinto L, Aisen PS (2010) Docosahexaenoic acid supplementation and cognitive decline in Alzheimer disease: A randomized trial. JAMA 304, 1903-1911.

[66] Jacobs DR Jr, Gross MD, Tapsell LC (2009) Food synergy: An operational concept for understanding nutrition. Am J Clin Nutr 89, 1543S-1548S.
[67] Scheltens P, Kamphuis PJ, Verhey FR, Olde Rikkert MG, Wurtman RJ, Wilkinson D, Twisk JW, Kurz A (2010) Efficacy of a medical food in mild Alzheimer's disease: A randomized, controlled trial. Alzheimers Dement 6, 1-10 e11.

[68] Estruch R, Ros E, Salas-Salvado J, Covas MI, Corella D, Aros F, Gomez-Gracia E, Ruiz-Gutierrez V, Fiol M, Lapetra J, Lamuela-Raventos RM, Serra-Majem L, Pinto X, Basora J, Munoz MA, Sorli JV, Martinez JA, Martinez-Gonzalez MA (2013) Primary prevention of cardiovascular disease with a Mediterranean diet. $N$ Engl J Med 368, 1279-1290. 